\title{
RUINAS Y PROPAGANDA DURANTE LA GUERRA CIVIL: EL EJEMPLO DE LA PRENSA VASCA ANTIFASCISTA ${ }^{1}$ (1936-1937) \\ RUINS AND PROPAGANDA DURING THE SPANISH CIVIL WAR: THE CASE OF THE BASQUE ANTIFASCIST PRESS (1936-1937)
}

\author{
Severiano Rojo Hernández \\ Aix Marseille Université \\ Telemme
}

Entregado el 22-12-2014 y aceptado el 4-12-2015.

\begin{abstract}
Resumen: A partir de un corpus de 289 fotografías publicadas cada miércoles en los principales diarios del País Vasco republicano, entre el inicio de la Guerra Civil (18 de julio de 1936) y la toma de Bilbao por las tropas franquistas (19 de junio de 1937), el autor analiza en qué medida la prensa y las autoridades vascas instrumentalizan las ruinas de guerra, cómo las imágenes de destrucción articulan un discurso político e identitario, cuyo objetivo es movilizar a los combatientes y a la retaguardia en contra de los rebeldes. El estudio intenta verificar hasta qué punto la presencia o la ausencia de ruinas en la prensa permite «decir y pensar» la guerra. Se trata de demostrar que la «presencia espectral» de las ruinas, o sea su relativa invisibilidad, constituye un ingrediente esencial de la propaganda empleada en Euskadi durante la guerra.
\end{abstract}

Palabras clave: Guerra Civil, prensa, fotografía, propaganda, ruinas de guerra, antifascismo

${ }^{1}$ Se utiliza el término «antifascista» para designar a una prensa que se consideró en gran parte, y según una cronología diferente, en lucha contra el fascismo, a pesar de que los militares rebeldes no fueran ideológicamente fascistas. 


\begin{abstract}
Examining a corpus of 289 photos released on Wednesday in the main newspapers of the republican Basque Country, between the beginning of the Civil war (July 18, 1936) and the capture of Bilbao by the pro-Franco troops (June 19, 1937), the paper analyzes to what extent the press and the Basque authorities use the war ruins, and how the destruction images articulate a political and identity speech, which aim is to mobilize the combatants and the rearguard against the rebels. The study shows how the presence or the absence of ruins in the press allows «to say and to think» the war-the «spectral presence» of the ruins or their relative invisibility representing an essential ingredient of the propaganda used in Basque Country during the war.
\end{abstract}

Key words: Civil war, press, photography, propaganda, ruins of war, antifascism 
Desde su creación y básicamente a partir del siglo XIX, la prensa desempeña un papel fundamental en la estructuración de nuestra percepción de los conflictos armados. Se trata de un fenómeno que, entre otros factores, se explica sencillamente por el hecho de que, cuando estalla una guerra, la población necesita mucha más información que en cualquier otro momento, porque los conflictos fragilizan las sociedades. La guerra genera un estado de incertidumbre e impide imaginar el presente y el porvenir sin amenazas. Reduce nuestra capacidad para creer en la realidad de los hechos y en la veracidad de la información, ya que con la guerra, la verdad se desvanece como nunca ${ }^{2}$. Frente a lo que Christophe Prochasson y Ana Rasmusen denominan la «inestabilidad de la realidad experimentada ${ }^{3}$, la prensa, gracias a su capacidad para aislar los hechos y formular una nueva realidad, propone un sistema que permite descifrar, en cierta medida, no sólo el acontecimiento guerrero, sino también la irracionalidad y la violencia extrema que generan los enfrentamientos armados. No obstante, los periódicos no transmiten una imagen totalizadora y absoluta de la realidad. Elaboran una representación de la guerra muy alejada de las experiencias de los combatientes ${ }^{4}$, sobre todo cuando se recurre a la fotografía. La fotografía inventa escenas diferentes ${ }^{5}$ y sólo propone «fragmentos de realidad $»^{6}$, que ayudan a la prensa a elaborar y a organizar un discurso sobre la actualidad. Los periódicos ordenan así el caos, combinando, jerarquizando y fraccionando la realidad, en especial, cuando la propaganda invade la prensa. Por lo tanto, la prensa, al igual que otros medios de comunicación, constituye un filtro que contribuye a la creación de una realidad social particularmente fluctuante en tiempos de guerra. Estos presupuestos resultan fundamentales para analizar el uso de las fotografías de ruinas de guerra, su publicación u ocultación, en la prensa vasca antifascista de la Guerra Civil (1936-1937) y para entender cómo la prensa transmite a sus lectores una imagen de la misma, eligiendo para ello la visión de sus primeras y principales consecuencias, o sea, la muerte y la destrucción.

${ }^{2}$ Christophe Prochasson y Anne Rasmussen, «La guerre incertaine», Vrai et faux dans la Grande Guerre, La Découverte, Paris, 2004, p. 10.

3 Ibidem

4 Ibidem, p. 16.

5 Jean Baudrillard, «Por qué la ilusión no se opone a la realidad», en Cuadernos de Información y Comunicación, n. ${ }^{\circ}$ 9, 2004, p. 194.

6 Expresión utilizada por Laurent Gervereau, «La guerre invisible», en Philippe Buton (Coord.), La guerre imaginée, Seli Arslan, Paris, 2002, p. 248. 
Para realizar el presente estudio, he elaborado un corpus de 289 fotografías publicadas cada miércoles ${ }^{7}$ en los principales diarios del País Vasco republicano, entre el inicio de la contienda (1 de julio de 1936) y la toma de Bilbao por las tropas franquistas (19 de junio de 1937) ${ }^{8}$. A partir de este corpus, he analizado en qué medida la prensa y las autoridades vascas instrumentalizan las ruinas de guerra, cómo las imágenes de destrucción articulan un discurso político e identitario, cuyo objetivo es movilizar a los combatientes y a la retaguardia en contra de los rebeldes. El estudio, pues, intenta verificar hasta qué punto la presencia o la ausencia de ruinas en la prensa permite «decir y pensar» la guerra. Se trata de demostrar que la «presencia espectral» de las ruinas, o sea su relativa invisibilidad, constituye un ingrediente esencial de la propaganda empleada en Euzkadi ${ }^{9}$.

\section{El 18 de julio de 1936 o el inicio de una transformación profunda del marco político y mediático del País Vasco}

El 18 de julio de 1936 genera en el País Vasco, al igual que en el resto del territorio español, una situación política y militar particularmente compleja. A pesar del fracaso del levantamiento, el territorio se fragmenta en función de las realidades sociopolíticas locales y de las estrategias y capacidad de los diferentes grupos para controlar el orden público. El País Vasco, por tanto, se divide fundamentalmente en dos zonas: el sur, o sea Alava, controlada por los militares rebeldes y sus aliados, y el norte, Vizcaya y Guipúzcoa, en donde las organizaciones y los partidos de izquierda respaldan a las autoridades y derrotan a los insurgentes gracias al apoyo - o mejor dicho a la neutralidad - del principal movimiento político de

7 La elección del miércoles se debe principalmente al hecho de que se trata de un día lo suficientemente alejado del fin de semana para que no interfieran las estrategias editoriales particulares desplegadas en ese momento. Se consideró que el miércoles era el día más neutral y, por tanto, el momento idóneo para poder analizar las prácticas propagandísticas cotidianas de la prensa.

${ }^{8}$ Corpus realizado a partir de fotografías publicadas cada miércoles entre el 18 de julio de 1936 y el 19 de junio de 1937, en los diarios Euzkadi (PNV), El Liberal (PSOE), Euzkadi Roja (PCE), CNT del Norte (CNT), Tierra Vasca (ANV), Unión (Republicanos), La Gaceta del Norte (derecha conservadora) y El Noticiero Bilbaíno (independiente).

9 A lo largo de este estudio, retomo el término «Euzkadi» con la ortografía de aquella época. 
la región, el PNV, cuyas dirección adoptó la línea defendida por los jelkides vizcaínos, que esperaban de esta manera conseguir la autonomía del País Vasco.

No obstante, la aparente rapidez con la que se delimitan las líneas divisorias de los dos campos no debe ocultar la complejidad de los fenómenos que se producen a partir del 18 de julio. De hecho, la postura oficial del PNV oculta la oposición de una parte importante de los nacionalistas vascos a cualquier tipo de compromiso o alianza con la izquierda y con la República española. Algunos líderes históricos como Luis Arana fueron partidarios de la neutralidad y parte de los nacionalistas alaveses y navarros dudaron a la hora de asumir la postura oficial del partido, hecho que llevó a algunos militantes de estos dos territorios a alistarse en los requetés.

Es fundamental, por otra parte, no olvidar el hecho de que, como en otras guerras civiles ${ }^{10}$, la ruptura de la legalidad vigente desembocó en un estallido de violencia que provocó la muerte de centenares de personas, tanto en la zona controlada por los rebeldes como en la que triunfó el denominado bando republicano ${ }^{11}$. Con el pronunciamiento militar y ante la disolución de la autoridad del Estado, el poder se fragmentó y se produjo una «paramilitarización de la gestión del orden público» ${ }^{12}$ que afectó al conjunto del País Vasco, a pesar de que en Vizcaya el gobernador civil, Echeverria Novoa, consiguió imponer su autoridad.

De hecho, en zonas como Guipúzcoa se multiplicaron los organismos de regulación del orden público y se produjo una fuerte movilización, impulsada por el deseo de neutralizar/aniquilar rápidamente al enemigo po-

10 Ver por ejemplo, Severiano Rojo Hernández y Eduardo González Calleja (Dir.), «Les guerres civiles, réflexions sur les conflits fratricides à l'époque contemporaine (Europe-Amérique)», Amnis, núméro extraordianio (http://amnis.revues.org/2260), Hispania Nova, n. 13 (http://e-revistas.uc3m.es/index.php/HISPNOV/index), 2015; Stathis Kalyvas, «The Ontology of «Political Violence»: Action and Identity in Civil Wars», Perspectives on Politics, vol. 1, n. ${ }^{\circ} 3$, sept. 2003; Philip B. Minehan, Civil War and World War in Europe. Spain, Yugoslavia, and Greece, 1936-1949, Basingstoke, Palgrave Macmillan, 2006; Eduardo González Calleja y Jordi Canal (eds.), Guerras civiles. Una clave para entender la Europa de los siglos XIX y XX, Madrid, Casa de Velázquez, 2012.

${ }^{11}$ Cfr. Paul Preston, El holocausto español. Odio y exterminio en la Guerra Civil y después, Madrid, Delbolsillo, 2013 (2011).

${ }^{12}$ Eduardo González Calleja, «Experiencia en combate. Continuidad y cambios en la violencia represiva (1931-1939)», en Javier Rodrigo (Coord.), en Retaguardia y cultura de guerra, 1936-1939, Ayer, n. ${ }^{\circ}$ 76, 2009, p. 56. 
lítico. Este proceso es sintomático de la lucha que se estableció entre las autoridades legales, los partidos, los sindicatos y los militares con los fines siguientes: primero, apoderarse o conservar el control de las instituciones tradicionalmente responsables del orden público; segundo, crear las nuevas estructuras encargadas de administrar los diferentes territorios mientras duren los acontecimientos; tercero, generar, en el caso de los militares y de los partidos radicales como los anarquistas o los requetés, una situación que hiciera imposible cualquier vuelta atrás ${ }^{13}$. Para alcanzar este objetivo, así como la homogeneización ideológica de la población ${ }^{14}$, el terror y el asesinato se generalizaron en algunas zonas del País Vasco, aunque la situación general de este territorio no se pueda comparar con la que imperó en regiones como Andalucía o Cataluña.

Este contexto explica en parte la estrategia del PNV en los meses de julio y agosto de 1936. Al principio del conflicto, los jelkides se movilizaron esencialmente para preservar el orden público y, en particular, para proteger a los eclesiásticos y los bienes de la Iglesia, saqueados en numerosos lugares de la España republicana. A pesar de su apuesta por la legalidad republicana, los nacionalistas vascos desconfiaban del gobierno republicano y de su capacidad para restablecer la autoridad del Estado. Por lo tanto, se quedaron a la expectativa y no participaron en los combates de los dos primeros meses de la guerra, lo que contribuyó a que las fuerzas rebeldes conquistaran Guipúzcoa en septiembre de 1936. Los recelos, sin embargo, no impidieron que se establecieran contactos entre los dirigentes del PNV y el gobierno de Largo Caballero. Madrid deseaba involucrar a los nacionalistas vascos en la lucha contra los militares sublevados, mientras que los jelkides esperaban conseguir la autonomía política del País Vasco ${ }^{15}$.

Las negociaciones finalizaron en el mes de septiembre con un acuerdo que desembocó en la participación de las milicias vascas en la guerra y en la proclamación, el 7 de octubre de 1936, de la autonomía vasca. Dicho acto consagra el nacimiento institucional de Euzkadi en lo que quedaba, en aquel momento, de territorio republicano en el País

13 Rafael Cruz, «Las campañas rebeldes de aniquilación del enemigo», en Javier Rodrigo (Coord.), Retaguardia y cultura de guerra, 1936-1939, Ayer, n. 76, 2009, p. 73.

${ }_{14} \mathrm{Cfr}$. Rafael Cruz, «Olor a polvora y patria. La limpieza política rebelde en el inicio de la Guerra de 1936», Hispania Nova, n. ${ }^{\circ}$ 7, 2007. http://hispanianova.rediris.es

15 Cfr. Santiago de Pablo, Ludger Mees, José A. Rodríguez Ranz, El péndulo patriótico. Historia del Partido Nacionalista Vasco, Barcelona, Crítica, 1999. 
Vasco, o sea Vizcaya. Bajo la dirección de José Antonio Aguirre, presidente de un gobierno de coalición en el que estaban representadas todas las fuerzas políticas vascas salvo los anarquistas, Euzkadi resistió a las tropas rebeldes. Estas lanzaron a partir de marzo de 1937 una ofensiva que provocó numerosas víctimas y destrucciones (Guernica, 26 de abril) y que desembocó en la toma de Bilbao, el 19 de junio. A lo largo de sus nueve meses de vida, esta entidad política se fue diferenciando cada vez más del resto del territorio republicano, en particular, por la política moderada de su gobierno en los ámbitos político, social, económico y religioso. Con el denominado «oasis vasco» se fracturó la España gubernamental, como muestran las escasas colectivizaciones que se produjeron en este territorio y la protección otorgada a la Iglesia y a sus miembros por las autoridades autonómicas. Este último elemento sirvió para cuestionar uno de los principales argumentos de los rebeldes a la hora de justificar su denominada cruzada: la defensa de la Iglesia.

Puesto que la guerra modificó profundamente el panorama político del País Vasco y provocó miles de víctimas entre la población, es obvio que su impacto en la prensa fuese también significativo. El control de la comunicación era prioritario para el conjunto de los grupos y fuerzas políticas involucrados en el conflicto. La prensa era considerada como esencial para orientar la opinión pública, administrar los diferentes territorios y, en definitiva, ganar la guerra. Esta percepción de la prensa, y de los medios de comunicación en general, permite entender por qué los rebeldes ocuparon durante las primeras horas del levantamiento los talleres y locales de los periódicos así como las emisoras de radio. Explica también las tensiones que generó el control de los mismos en el bando republicano y la rapidez con la que algunos partidos y sindicatos de izquierda incautaron los periódicos considerados como facciosos. Esta carrera contra reloj era la consecuencia de una lucha encarnizada por el dominio del espacio público, para lo cual era estratégicamente imprescindible el control de los medios de comunicación. Por consiguiente, a partir del 18 de julio, los periodistas y propietarios de periódicos fueron perseguidos tanto en la zona rebelde como en la zona gubernamental. Algunos fueron detenidos, otros asesinados (como José María Urquijo, propietario de La Gaceta del Norte). La depuración del personal de prensa se generalizó por todo el territorio, se multiplicaron las incautaciones de periódicos y parte de la prensa que existía antes de la guerra acabó desapareciendo. Fue un período de profunda inestabilidad y de cambio. 
En Alava, por ejemplo, el periódico pro-republicano, La Libertad, fue incautado y sustituido, en enero de 1937, por el diario Norte de obediencia falangista ${ }^{16}$. En San Sebastián cerraron todos los periódicos y las autoridades publicaron un solo diario, Frente Popular ${ }^{17}$, hasta septiembre de 1936, momento en que los rebeldes tomaron la ciudad ${ }^{18}$. En Bilbao, la situación fue algo distinta. Se incautaron los diarios y publicaciones de derecha, en particular los diarios La Gaceta del Norte, El Pueblo Vasco y El Nervión junto al periódico independiente El Noticiero Bilbaíno. Sin embargo, las autoridades siguieron publicándolos para crear la impresión de que en Euzkadi las fuentes de información eran plurales y educar a los lectores conservadores inculcándoles los valores republicanos ${ }^{19}$. Este espacio de aparente libertad informativa tuvo escasa vida. A partir de noviembre, las autoridades vascas cambiaron de estrategia y eliminaron progresivamente las antiguas cabeceras de derecha que habían logrado sobrevivir en el País Vasco. Por su parte, la prensa de izquierda y nacionalista vasca contribuyó de manera activa en la organización y movilización de las tropas y de la retaguardia. Nacía de esta manera una prensa vasca antifascista estructurada en torno a un amplio abanico ideológico (de la extrema izquierda a la derecha nacionalista vasca), una prensa única a lo largo del conflicto y que se consolidó con la creación de numerosas cabeceras tanto en 1936 como en 1937 (por ejemplo, Euzkadi Roja, CNT del Norte, Unión, Gudari) ${ }^{20}$. Sin embargo, este proceso se desarrolló junto otro fenómeno: el incremento de la censura ${ }^{21}$.

16 Santiago de Pablo, «La estructura de la prensa vasca durante la Segunda República. El País Vasco y Alava», en Kultura, n. ${ }^{\circ}$ 1, 1990, p. 106.

17 Félix Luengo Teixidor, «La prensa guipuzcoana durante la Guerra Civil (19361939)», en Manuel Tuñón de Lara, Carmelo Garitaonandia, José Luis de la Granja y Santiago de Pablo, (Coords.), Comunicación, cultura y política durante la II República y la Guerra Civil, II encuentro de historia de la prensa, País Vasco (1931-1939), t. I, Universidad del País Vasco, Bilbao, 1990, p. 178.

${ }_{18}$ Cfr. Carmelo Garitaonandia, «Información, propaganda y guerra de ondas en el País Vasco (1936-1937)», en Muga, n. ${ }^{\circ}$ 62, 1987, p. 33.

19 Archivo del Nacionalismo, Fondo Guerra en Euskadi, K. 69, C. 11.

${ }^{20}$ Cfr. Santiago de Pablo, «Los medios de comunicación», en José Luis de la Granja y Santiago de Pablo (Coords.), Historia del País Vasco y Navarra en el siglo XX, Biblioteca Nueva, Madrid, 2002, pp. 390-391.

21 Ver las medidas adoptadas por las autoridades vascas en Centro Documental de la Memoria Histórica, PS Santander, Leg. 13, Exp. 13 ; PS Bilbao, Caja 113, Exp. 10. 


\section{Las ruinas de guerra en la prensa vasca antifascista: entre visibilidad $\mathbf{y}$ «espectralidad»}

La Guerra Civil española constituye un hito en la historia de la comunicación. Durante el conflicto, el incremento y los avances técnicos de los medios de comunicación (prensa, cine, radio) unidos a la evolución de las prácticas comunicativas forjaron nuevas técnicas propagandísticas que desempeñaron un papel fundamental en el desarrollo de la guerra. A ello contribuyó asimismo la fotografía, que ya se había convertido antes del conflicto en un componente periodístico esencial, dada su mayor presencia en la prensa y su influencia en la lectura. La fotografía, bien se sabe, imprimió un nuevo sesgo al proceso de comunicación y orientó los enfoques que de la actualidad se quisieron divulgar. Por tanto, los clichés publicados durante la Guerra Civil transformaron el conflicto en «una guerra de imágenes y en imágenes» y alimentaron un imaginario como el generado, para citar un ejemplo, por las célebres fotografías de Robert Capa ${ }^{22}$, tantas veces reproducidas. No fue éste un fenómeno novedoso en 1936, sino que ya empezaba a formar parte de la tradición mediática anterior a la Guerra de España, tradición que recogía arquetipos y representaciones de la cultura occidental. Las imágenes de ruinas de guerra, en particular, se habían convertido en objetos convencionales para el lector de la prensa a partir de la Guerra de Crimea y, concretamente, durante la Primera Guerra Mundial ${ }^{23}$, dos enfrentamientos en los cuales las ruinas fueron vinculadas a cierta estética, que contribuyó no solamente a difundir visualmente la naturaleza intrínseca de la guerra sino también los rasgos que singularizaban al enemigo.

En el caso de la Guerra Civil tal y como se desarrolla en Euzkadi, la publicación de fotografías de ruinas de guerra está en perfecta adecuación con esta tradición, que pretende, entre otras cosas, generar un estereotipo en el que se asocia el adversario con el terror y la destrucción. Sin embargo, si durante la Primera Guerra Mundial el tema de las ruinas «no fue prohibido, sino más bien valorizado», hasta el punto de que la

${ }^{22}$ François Fontaine, «La guerre d'Espagne : une guerre d'images», en Thérèse Blondet-Bisch, Robert Frank y Laurent Gervereau (Coords.), Voir, ne pas voir la guerre. Histoire des représentations photographiques de la guerre, Somogy, Paris, 2001, p. 85.

${ }_{23}$ Cfr. Emmanuelle Danchin, «Destruction du patrimoine et figure du soldat allemand dans les cartes postales de la Grande Guerre», en Rojo Hernandez, Severiano (Coord.), Culture de guerre. Représenter et penser l'affrontement (XIXe siècle à nos jours), Amnis, n. ${ }^{\circ} 10,2011$. 
censura francesa autorizó la publicación de miles de fotografías y de cartas postales que mostraban las destrucciones provocadas por la artillería alemana ${ }^{24}$, en Euzkadi, en cambio, se produjo una evolución notable en el uso de las fotografías y los valores que éstas difundían.

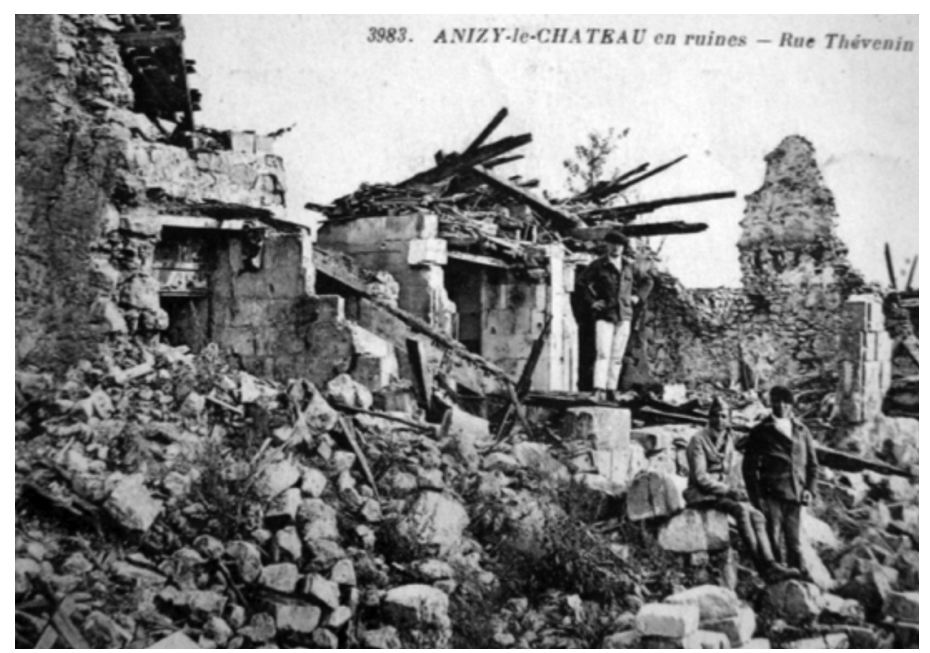

Carta postal, Caja A, Historial de la Grande Guerre (Péronne), SA.

La publicación de imágenes ruinas de guerra en los diarios vascos estaba estrictamente controlada y su utilización fue poco frecuente. De hecho, de las 289 fotografías que componen nuestro corpus, solamente $13,5 \%$ están dedicadas a las destrucciones provocadas durante el conflicto ${ }^{25}$, un dato ampliamente inferior al porcentaje de clichés (50\%) inventariado por Joëlle Beurier en los periódicos alemanes de la Primera Guerra Mundial26.

A través del análisis de las fotografías que proponían los diarios vascos se observa la aparición de nuevas prácticas, debido en parte al peso de

${ }^{24}$ Ibidem, p. 25.

${ }^{25}$ La mayor parte de ellas fue publicada en El Liberal (41\%). El resto se repartió de la manera siguiente: Tierra Vasca (18\%), Euzkadi (15\%), Euzkadi Roja y Unión (13\%), La Gaceta del Norte, El Noticiero Bibaíno y CNT del Norte (0\%).

${ }_{26}$ Joëlle Beurier, Images, violence et masculinités. Les presses illustrées française et allemande en Grande Guerre, Manuscrito de tesis, European University Institute, 2007, p. 402. 
la censura y de la propaganda, pero en especial, a la voluntad de deconstruir la realidad y de vincular el conflicto a una representación idealizada y mitificada de Euzkadi. Así, las imágenes de ruinas surgen y desaparecen según las prioridades políticas y militares del momento o, también, en función de las estrategias de desmaterialización y de reorientación del significado del conflicto en las que se insertan los periódicos.

Por ende, la evolución entre visibilidad y «espectralidad» de las fotografías de ruinas no obedece a una lógica lineal, por lo que el corpus fotográfico no se puede organizar ni clasificar según criterios absolutos. Al centrar el análisis en los daños provocados por el enfrentamiento, se observa que la noción de visibilidad se desvanece y se vuelve particularmente aleatoria por razones diversas. En el caso de los clichés que presentan claramente la violencia de las destrucciones, la función informativa va más allá de las imágenes de devastación presentes en primer plano. Es más, las impresiones que estas fotografías producen a primera vista pierden importancia ante la capacidad de evocación y las múltiples lecturas que sugieren:

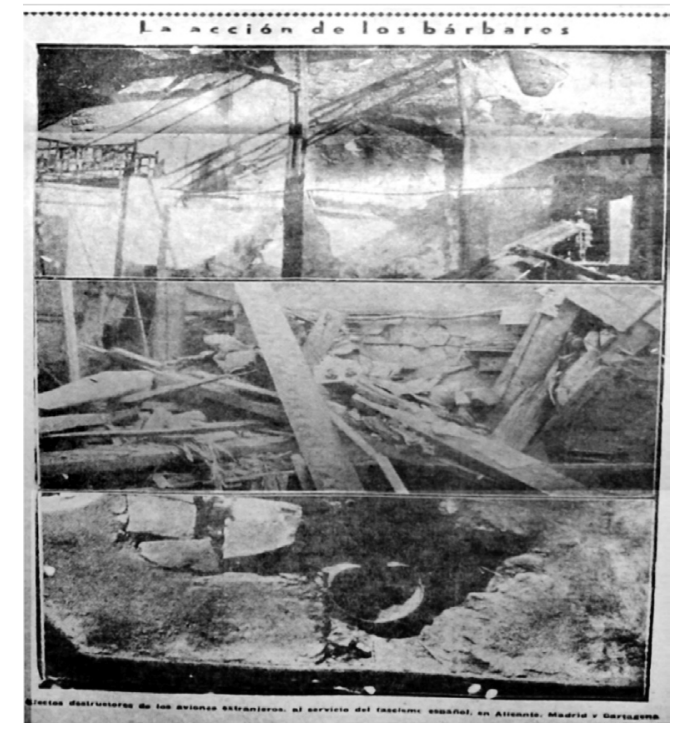

El Liberal, 10 de marzo de 1937, p. 6.

«Efectos destructores de los aviones extranjeros al servicio del fascismo español, en Alicante, Madrid y Cartagena.» 
Las fotografías de ruinas parecen haber sido puestas en escena y esbozan un «paisaje-espectáculo» con el objetivo de ofrecer al lector un discurso de múltiples dimensiones. Los clichés alimentan sobre todo una representación animalizada del enemigo y asociada a la imagen tradicional del bárbaro, lo que facilita su exclusión de la humanidad y de la civilización. Sin embargo, aunque las ruinas de guerra sirvan de instrumento de denuncia y de reorientación de la percepción de los militares rebeldes, permiten también situarse ideológicamente en el conflicto, pues sirven de elementos referenciales ya que generan imágenes especulares fundamentales para definir la identidad de los antifascistas. De ahí que las ruinas pierdan su materialidad y su sentido primero - el caos y la destrucción - para proponer un discurso propagandista estructurado en torno a la exhibición de cierto tipo de violencia, que nada tiene que ver, idealmente, con los gudaris y los milicianos de la República. Los clichés se insertan de esta manera en un proceso de verbalización del odio y, por lo tanto, de una cultura de guerra imprescindible para movilizar a los combatientes y a la retaguardia' 27 .

Las fotografías, por otra parte, son a menudo herméticas y su lectura no resulta fácil, en especial, cuando se trata de fotomontajes que presentan fragmentos de edificios derruidos. La utilización de estos clichés basados en los efectos directos de los bombardeos dificulta la identificación de las ruinas, lo que le permite a la prensa plegarse a las exigencias de la censura. Dentro de este esquema, el pie de foto desempeña un papel fundamental. Su contenido incrementa la confusión, como lo subraya la fotografía anterior,

27 Sobre el empleo propagandístico de los bombardeos sobre objetivos civiles, ver: Robert Stradling, Your Children Will Be Next: Bombing and Propaganda in the Spanish Civil War 1936-1939, Cardiff, University of Wales press, 2008; Martin Minchom, Spain's Martyred Cities: From the Battle of Madrid to Picasso's Guernica, Brighton, Sussex Academic Press/Cañada Blanch, 2015. Sobre el uso de la fotografía e imágenes en la propaganda durante la Guerra Civil ver, por ejemplo, Antonio Pantoja Chaves, «Fotografía y propaganda. Imágenes de la Guerra Civil española», Propaganda de guerra, Salamanca, Consorcio Salamanca 2002, 2002; Eliseo Trenc Ballester, «L'affiche anarchiste de la guerre civile espagnole 1936-1939», La guerre imaginée. L'historien et l'image, Buton, Philippe (dir.), Paris, Seli Arslan, 2002; Josu Bilbao Fullaondo, «Fotografía y Guerra Civil», en Carmelo Garitaonandia y José Luis de la Granja (dir.), La Guerra Civil en el País Vasco 50 años después Bilbao, Universidad del País Vasco, 1987; «La fotografía como sistema de propaganda en la prensa vasca (1931-1937)», en Manuel Tuñón de Lara, Carmelo Garitaonandia, José Luis de la Granja y Santiago de Pablo (dir.), Comunicación, cultura y política durante la II República y la Guerra Civil, II encuentro de historia de la prensa, País Vasco (1931-1939), t. I, Bilbao, Universidad del País Vasco, 1990; Fotografía y fotógrafos en el País Vasco, Baracaldo, Librería San Antonio, 2002. 
la cual plantea una pregunta particularmente interesante: ¿cuántos lectores en el País Vasco de 1937 eran capaces de identificar esas ruinas y de situarlas geográficamente? El cliché garantiza la visibilidad de las ruinas, pero la lectura de las imágenes pone en entredicho la eficacia de esa visibilidad. Esta, desde luego, tiene una importancia relativa, ya que lo que propone la prensa es un deslizamiento semántico para que cada fotografía de ruina remita metonímicamente al conjunto de las destrucciones provocadas por los militares rebeldes. Las ruinas, de este modo, se diluyen unas en otras y forjan la «huella» de una voluntad programada de aniquilación, no solamente de los republicanos, sino también del pueblo vasco.

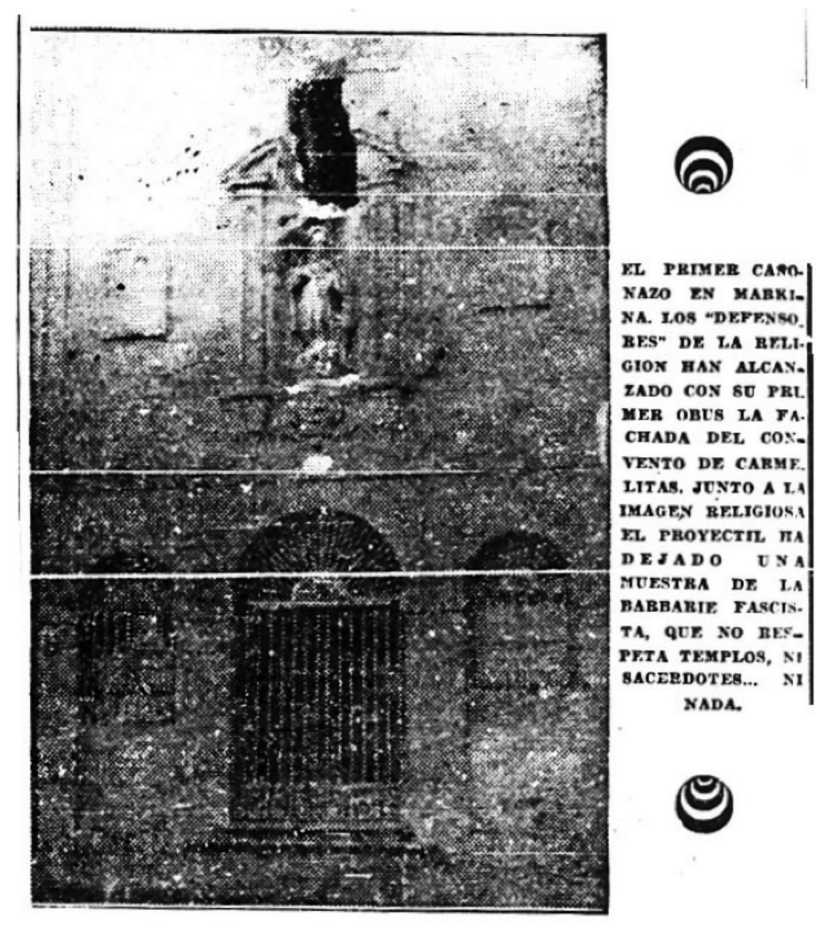

Euzkadi, 17 de février de 1936, p. 6. «El primer cañonazo en Markina. Los «defensores» de la religión han alcanzado con su primer obus la fachada del convento de carmelitas. Junto a la imagen religiosa el proyectil ha dejado una muestra de la barbarie fascista, que no respeta templos ni sacerdotes... ni nada.» 


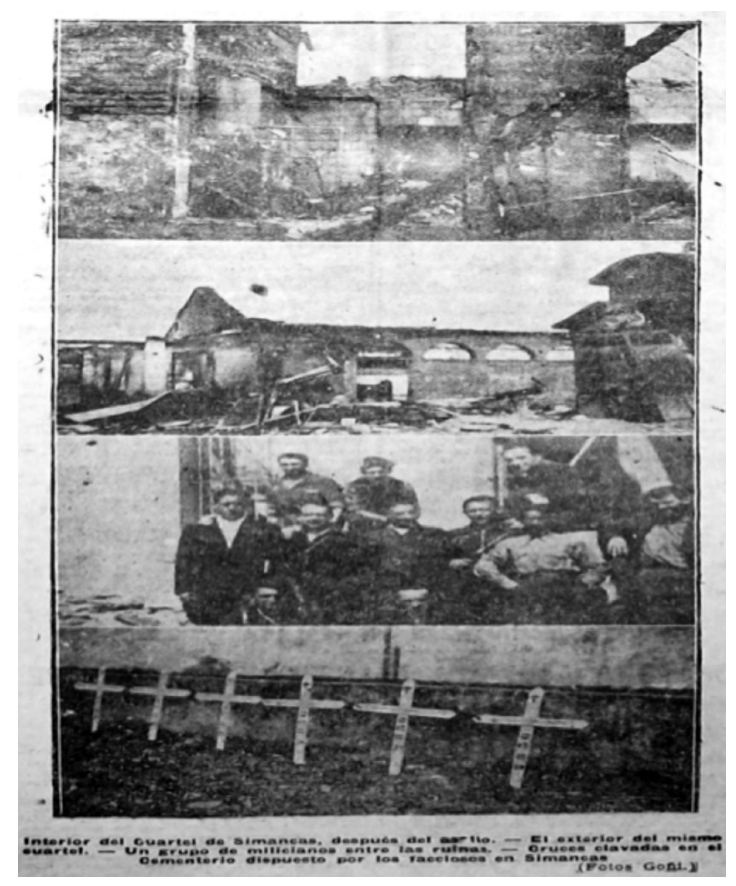

El Liberal, 26 de agosto de 1936, p. 3.

«Interior del cuartel de Simancas después del asalto.

-El exterior del mismo cuartel. - Un grupo de milicianos entre las ruinas.

- Cruces elevadas en el cementerio dispuesto por los facciosos en Simancas.»

El corpus utilizado para este estudio pone también de realce las preferencias de los diarios y de la censura en materia de comunicación, prioridades que condicionan la visibilidad y la lectura iconográfica del enfrentamiento desde el punto de vista geográfico y cronológico. La prensa publica en general fotografías que muestran ruinas generadas por el conflicto en las otras regiones españolas (67\%). Los clichés que muestran los daños sufridos por las ciudades vascas no son muy abundantes $(27 \%)^{28}$. Además, las imágenes que transmiten el grado de violencia y de destruc-

${ }^{28} 6 \%$ de las fotografías no pueden ser identificadas desde el punto de vista geográfico. 
ción más elevado, al margen de las fotografías del bombardeo de Guernica (26 de abril de 1937), reproducen normalmente centros urbanos e edificios localizados fuera del País Vasco.

A través de la prensa el lector accede, pues, a lo que podríamos denominar una cartografía diseminada de las devastaciones de la guerra. Esta cartografía diseminada no proporciona una visión global de la situación de la España republicana, ni tampoco guarda relación con Euzkadi, principal centro de interés del lector vasco. Por estar vinculada aparentemente a los acontecimientos que se producen en el momento en que se publica el diario, dicha cartografía alimenta sobre todo una representación del conflicto en la que la violencia más implacable afecta al «otro», es decir, a los habitantes de ciudades como Madrid, Barcelona u Oviedo. La violencia extrema y el caos que sugieren los clichés de los edificios más dañados son expulsados fuera del espacio inmediato del lector vasco, puesto que la dimensión ansiogénica de esos clichés había sido evaluada, filtrada y expurgada de antemano en todos los periódicos.

Publicar las fotos de un edificio de Madrid devastado por las bombas permite relativizar las destrucciones que se producen en Euzkadi, unas destrucciones de las cuales, desde luego, sólo se ve una parte insignificante. Por consiguiente, la prensa genera en el lector lo que podríamos denominar una visión présbita. La localización geográfica de las destrucciones determina su grado de visibilidad, ya que aumenta con la lejanía y se reduce con la proximidad. El objetivo de dicha estrategia de comunicación reside en preservar la moral de las tropas y de la retaguardia, y para ello crea un discurso que se estructura en torno a dos nociones fundamentales, el alejamiento espacial y la seguridad.

Esta estrategia, sin embargo, fracasa durante la primavera de 1937, período a partir del cual el relato iconográfico sobre el enfrentamiento en el País Vasco se adentra en una nueva temporalidad. El número de fotografías de ruinas aumenta y la guerra transforma las páginas de todos los periódicos en campos de batalla virtuales que reflejan las importantes evoluciones que se producen en el frente: el 31 de marzo de 1937, tras largos meses de combates en los suburbios de Madrid, los rebeldes lanzan una gran ofensiva para conquistar Bilbao y su industria y eliminar los últimos reductos republicanos del norte de España. La ofensiva provoca miles de víctimas y daños considerables. El Bombardeo de Guernica (26 de abril de 1937) constituye sin duda el símbolo por antonomasia de la violencia extrema que sacude durante este período el norte de España y particularmente Euzkadi. 


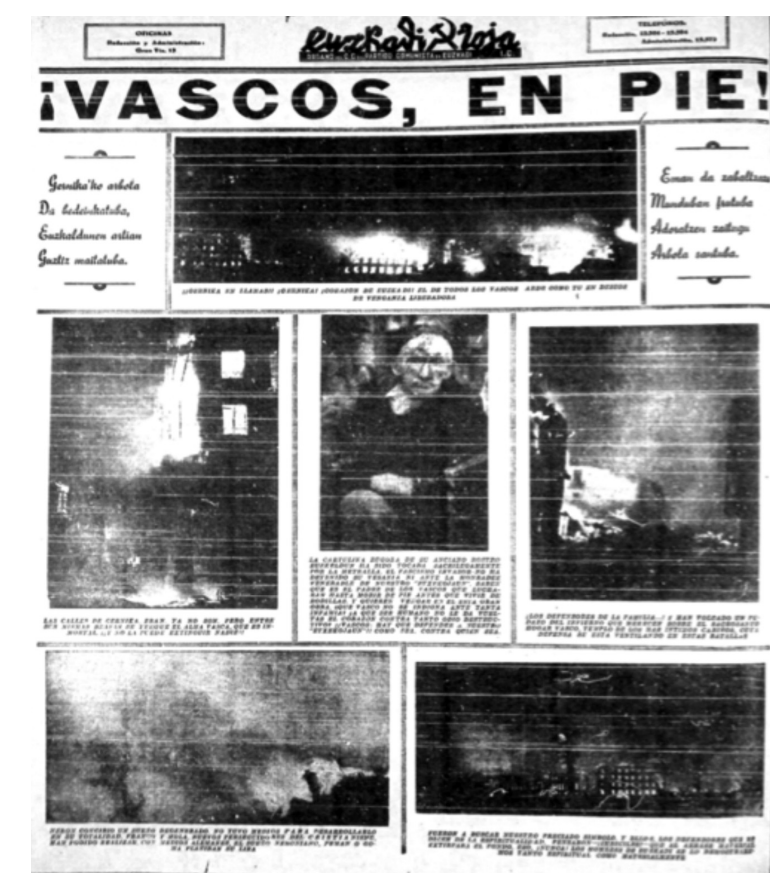

«iVascos en pie!», Euzkadi Roja, 28 de abril de 1937, p. 8

Las fotografías del incendio de Guernica constituyen el punto culminante de una campaña de propaganda en la cual las ruinas son instrumentalizadas para denunciar al enemigo y para movilizar a los antifascistas, pero también para hacer reaccionar a la opinión internacional e incitar a las principales potencias militares de la época (Francia e Inglaterra) a intervenir en el conflicto ${ }^{29}$. Por consiguiente, las imágenes del bombardeo del símbolo de las libertades vascas son ampliamente difundidas en el ex-

${ }^{29}$ Cfr. Carmelo Garitaonandía, «Información y propaganda en torno al bombardeo de Guernica», en Manuel Tuñon de Lara (Dir.), Gernika : 50 años después (1937-1987). Nacionalismo, República, Guerra Civil, Universidad del País Vasco, San Sebastián, 1987; Severiano Rojo Hernandez, «Guernica : les presses basque et française face au bombardement», en El Argonauta Español, n. ${ }^{\circ}$ 1, enero de 2004. http://argonauta.imageson.org/document44. html; George Lowther Steer, El arbol de Guernica. The Tree of Guernica. A Field Study of Modern War, sl, Ediciones Gudari, 1963; Herbert R. Southworth, La destruction de Guernica. Journalisme, diplomatie, propagande et histoire, Paris, Ruedo Ibérico, 1975. 
tranjero. En Euzkadi, no obstante, desaparecen rápidamente de la prensa local porque el Gobierno vasco quiere impedir que el pánico cunda entre la población de Bilbao y dificulte aún más la trágica situación de la retaguardia. En el País Vasco republicano, Guernica se convierte por tanto en un objeto que pertenece esencialmente a la esfera de lo escrito, o sea presente únicamente en los artículos de prensa y los testimonios escritos - así como radiofónicos - de los supervivientes. Desde el punto de vista visual, las ruinas de la capital foral de Vizcaya desaparecen, aun cuando formen parte del trasfondo imaginario de las pocas fotografías que publica la prensa sobre los bombardeos de Bilbao y su comarca:

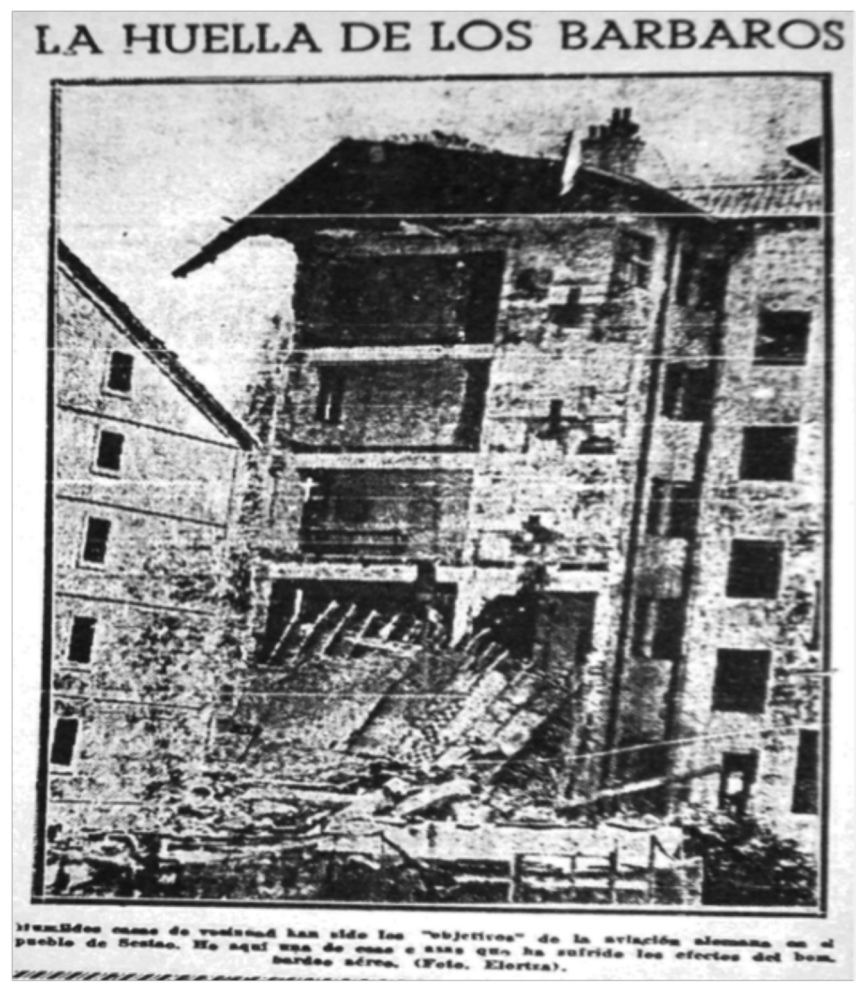

«La huella de los bárbaros», Euzkadi, 26 de mayo de 1937, p. 6. «Humildes casas de vecindad han sido el «objetivo» de la aviación alemana en el pueblo de Sestao. He aquí una de esas casas que ha sufrido los efectos del bombardeo aéreo.» 
La destrucción de Guernica constituye el prisma a través del cual se analizan y se valoran las destrucciones de la que es víctima Euzkadi y, más allá, la España republicana. Para entender las causas de esta evolución, o sea, por qué las ruinas de Guernica alcanzan esta dimensión en la prensa y se convierten en un símbolo que escapa de alguna manera a los antifascistas vascos, hay que hacer hincapié tanto en la importante campaña de propaganda que organizan las autoridades vascas en España y en el extranjero, como en la interpretación del bombardeo, que realiza una parte de la opinión pública y de la prensa a partir de unos parámetros anacrónicos. Esos parámetros, precisamente, hacen que se eliminen numerosos elementos indispensables para la restitución de la realidad histórica. Se sumerge al lector en una escenografía característica de la Primera Guerra Mundial, en la que la aviación italiana desaparece prácticamente y la Legión Cóndor se convierte en la principal responsable del ataque contra el símbolo de los fueros vascos. Se reactivan, de esta manera, algunas de las principales representaciones de la Gran Guerra, en particular la idea de que se está produciendo una guerra de civilizaciones. Los alemanes son vándalos, que aniquilan a la población civil inocente y los símbolos de su identidad, ya que destruyen metódicamente su patrimonio cultural ${ }^{30}$. Guernica se convierte así en una ciudad mártir, víctima de un crimen de guerra, al igual que lo fueron en su época Reims y Lovaina.

El discurso sobre Guernica y las representaciones que difunde ponen de realce un aspecto fundamental de la Guerra Civil: se considera que este conflicto se inserta en un continuum, o sea que forma parte de un conflicto que rebasa los límites de la península y que empezó antes del 18 de julio de 1936. Por consiguiente, la prensa divulga la idea de que el conflicto español constituye un fragmento de un fenómeno mucho más amplio, que Enzo Traverso ${ }^{31}$ y Eric Hobsbawm ${ }^{32}$ denominan «guerra civil europea», una interpretación que corrobora este estudio así

30 Cf. Bénédicte Grailles, «La reconstruction des villes du Nord. Mémoire et identité», en Philippe Chassaigne y Jean-Marc Largeaud (Coords.), Villes en guerre, Armand Colin, Paris, 2004, p. 260.

31 Enzo Traverso, A Feu et à sang. De la guerre civile européenne 1914-1945, Stock, Paris, 2007; Ver también, Javier Rodrigo, «Retaguardia: un espacio de transformación», en Javier Rodrigo (Coord.), Retaguardia y cultura de guerra, 1936-1939, Ayer, n. ${ }^{\circ}$ 76, 2009, p. 29.

32 Eric J. Hobsbawm, L'Âge des extrêmes. Histoire du court Xxe siècle, Editions complexes, Paris, 1994. 
como la importancia que reviste la Primera Guerra Mundial en periódicos como Unión ${ }^{33}$.

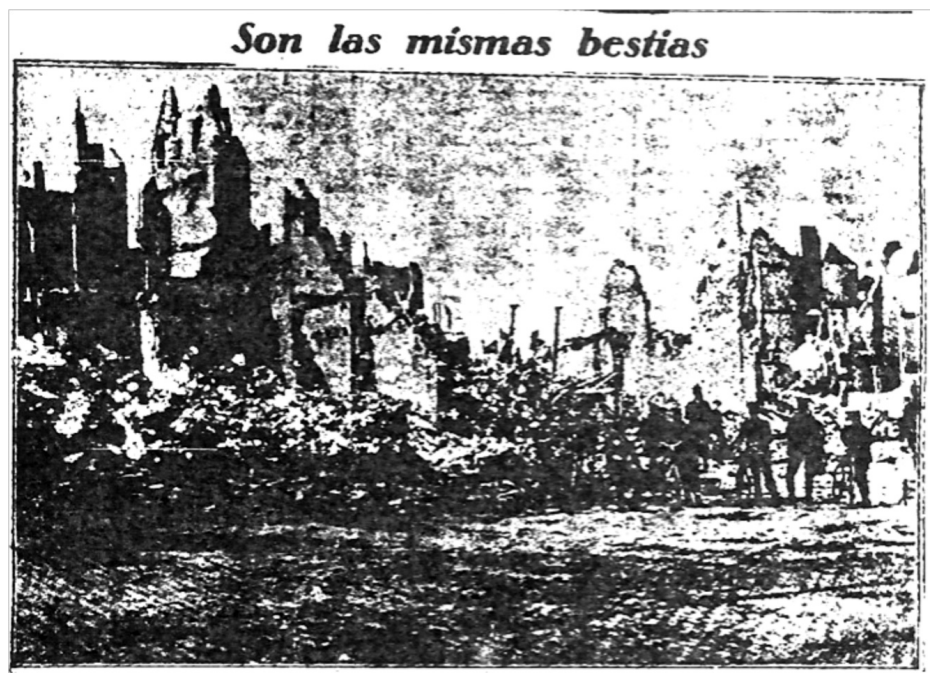

ES ESTA UMA VIESA ESTAMPA DE LA GUERRA EUROPEA. HAM PAEADO LOS AVIOMES MLEMA. WES. HAN DESHECHO UMA CIUDAD. HAN IATADO YWUERES Y WIMOS. WO ES WADA. ELLOS WAM A SALVAR LA CIVILIZACION OCCIDENTAL. WO APUAARSE. NO ES MADA. LUEOO, MAN THA NOOU. RRIDO LOS ANOS. LOS AVIONES ALEMANES SE HAN PERFEOCIONADO. ELLOS SIOUEM TAN BES. BELAA, SE REPRODUCE Y RECRUDECE EN DORAMOO EIBAR, GUERMIOA SON LAS PISMAS MIE. MAS CON TEJORS AVONES.

«Son las mismas bestias», Unión, 28 de abril de 1937, p. 1. Es ésta una vieja estampa de la guerra europea. Han pasado los aviones alemanes. Han deshecho una ciudad. Han matado mujeres y niños. No es nada. Ellos van a salvar la civilización occidental. No apurarse. No es nada. Luego, han transcurrido los años. Los aviones alemanes se han perfeccionado. Ellos siguen tan bestias como siempre. Y esta vieja estampa de desolación recogida en un pueblecito belga, se reproduce y recrudece en Durango, Eibar, Guernica...

Son las mismas hienas con mejores aviones.»

33 Este diario publicó numerosos artículos en los que utilizaba la Primera Guerra Mundial para comentar la evolución de los acontecimientos durante la Guerra Civil o para explicar prácticas como los bombardeos de las ciudades. Cfr. «El mayor peligro de la guerra. Los centros urbanos e industriales bajo la amenaza aérea», Unión, 31 de marzo de 1937, p. 4. El Liberal y Euzkadi Roja compararon también la Guerra Civil con la Primera Guerra Mundial. 
La Primera Guerra Mundial se convierte en un referente que orienta las principales representaciones que se transmiten sobre la guerra en Euzkadi. Otras prácticas comunicativas lo corroboran asimismo, tales como la publicación en la prensa nacionalista y en los diarios incautados por las autoridades vascas - o incluso en la prensa rebelde - de numerosas fotografías a primera vista anacrónicas, pero cuya dimensión simbólica articula un discurso esencial para forjar una imagen distinta de la guerra y de sus consecuencias.

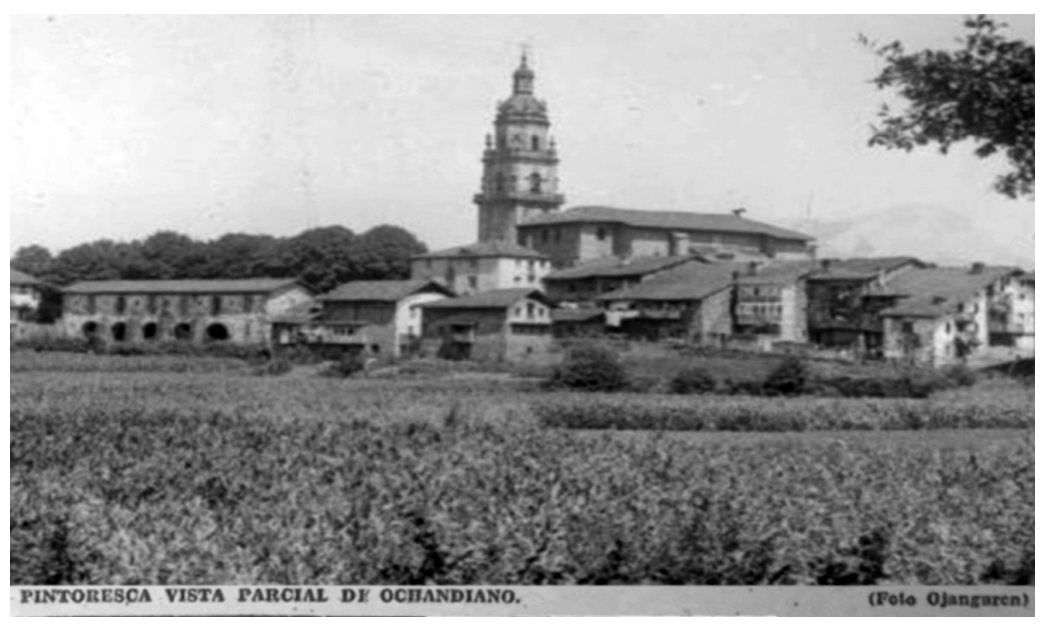

«Pintoresca vista parcial de Ochandiano», El Noticiero Bilbaíno, 11 de noviembre de 1936, p. 1.

Publicadas durante los primeros meses de la guerra, estas fotografías son sintomáticas de una voluntad de «decir» la guerra aludiendo a un período anterior al conflicto. Aparecen aisladas en la hoja del periódico, como reliquias, con el objetivo de sugerir indirectamente, gracias a su dimensión anacrónica y atemporal, las devastaciones que provoca la guerra. Aluden, en particular, a la desaparición de un País Vasco idealizado, cuyo principal modelo no es el mundo urbano sino la sociedad rural tradicional, acorde con los fundamentos de la ideología nacionalista vasca. Estas fotografías de Indalecio Ojanguren - totalmente descontextualizadas en la medida en qué su autor las tomó entre 1918 y 
1919 como documentos etnográficos relativos a los usos y las costumbres del campo vasco de aquella época - recuerdan algunas prácticas de la prensa alemana, analizadas por Joëlle Beurier en su estudio sobre las imágenes y la violencia en la prensa ilustrada francesa y alemana de la Primera Guerra Mundial ${ }^{34}$. La autora señala la existencia de clichés que «representan, de manera totalmente anacrónica, paisajes espléndidos» ${ }^{35}$, que «transmiten valores positivos en un contexto marcado por su dimensión negativa ${ }^{36}$.

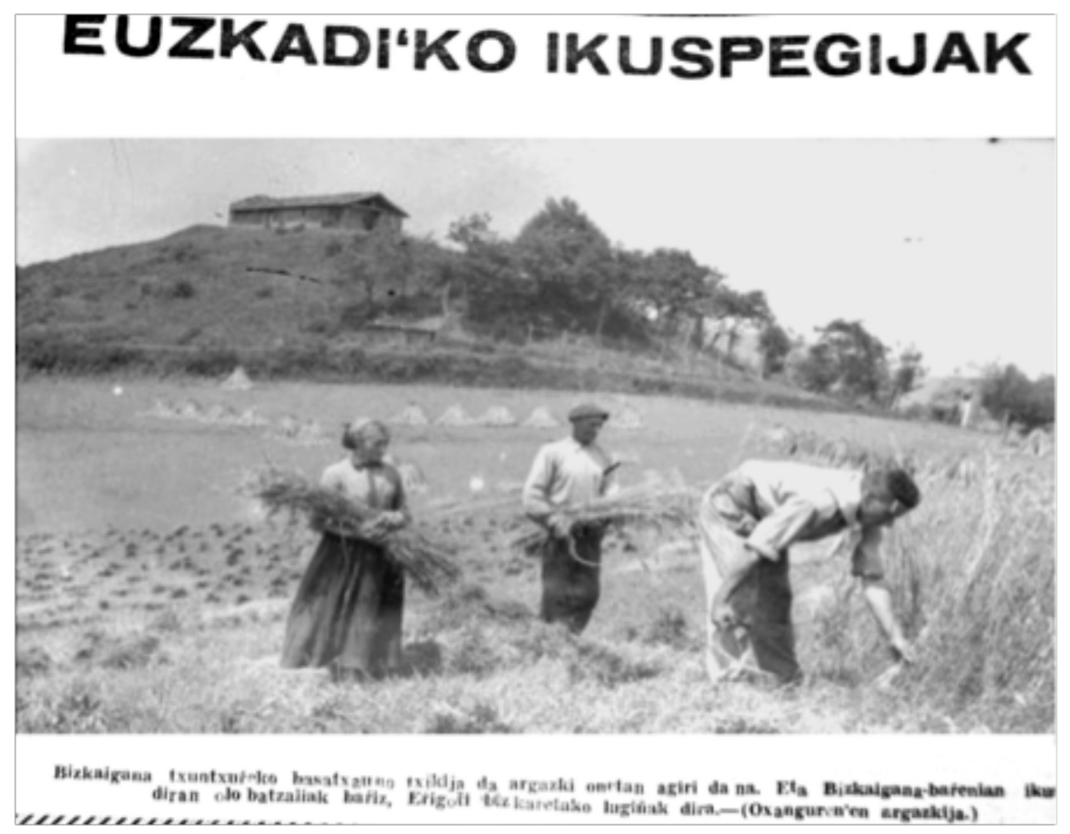

«Paisajes de Euzkadi», Euzkadi, 2 de diciembre de 1936, p. 8. «En esta foto se puede ver la ermita situada en la cima del Bizkargarai. Los segadores que aparecen en la foto son campesinos de Erigoiti.»

\footnotetext{
34 Cfr. Joëlle Beurier, op. cit.

35 Ibidem, p. 412.

36 Ibidem, p. 414.
} 


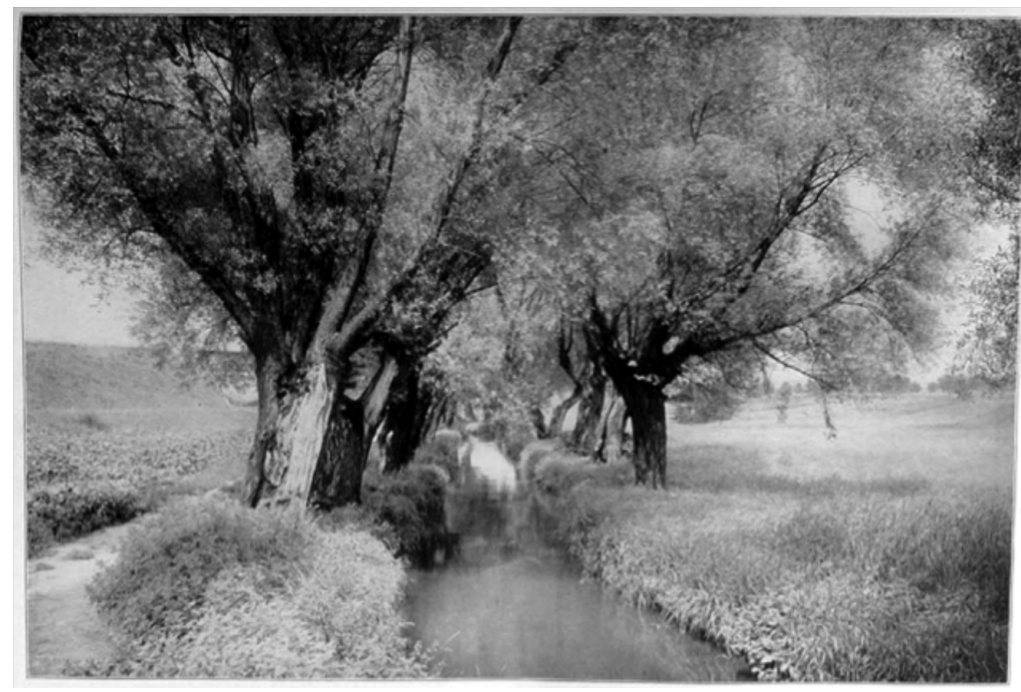

Illustrirte Zeitung, 14 de junio de 1917, p. 794.

Estas imágenes, en su opinión, justifican el sacrificio de los combatientes al mostrar todo lo que preservan los soldados alemanes. Se trata pues «de conseguir que la vista se aparte de la monstruosidad del conflicto para que se centre claramente en las ventajas que conlleva el enfrentamiento y, de esta manera, convertir la guerra en algo trivial» ${ }^{37}$. El caso vasco es semejante. Las fotografías de Ojanguren desempeñan la misma función. Describen un País Vasco mítico, amenazado por una invasión y que hay que defender a cualquier precio. Sin embargo, en Euzkadi, la prensa va más lejos que la prensa alemana de la Primera Guerra Mundial, puesto que manipula las fotografías para que el espectro de los combates y de las devastaciones se infiltre en las imágenes y reoriente el primer significado de los clichés. Los paisajes y los edificios ya no son el reflejo de la realidad, sino el espectro de lo que fueron en su tiempo, antes de que empezara la guerra. Para conseguir este resultado, los diarios introducen un nuevo elemento, el pie de foto, ausente en las fotografías originales:

\section{Ibidem}




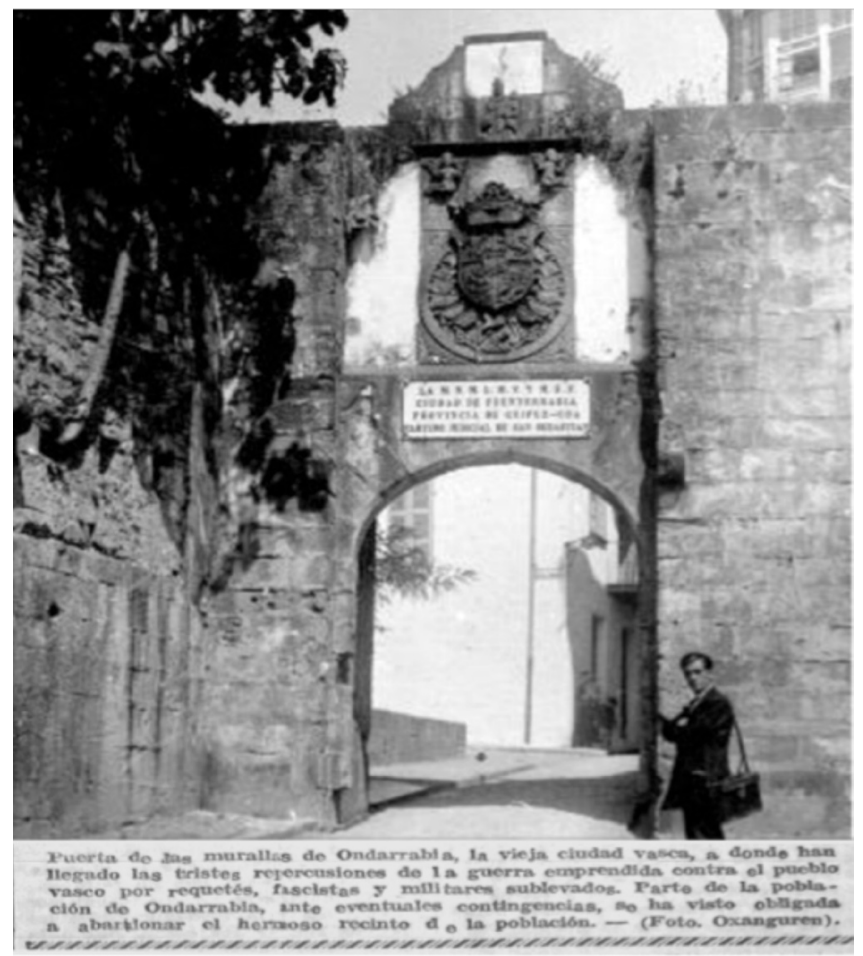

Euzkadi, 9 de septiembre de 1936,p. 6. «Puerta de las murallas de Ondarrabia, la vieja ciudad vasca, a donde han llegado las tristes repercusiones de la guerra emprendida contra el pueblo vasco por requetés, fascistas y militares sublevados.

Parte de la población de Ondarrabia ante eventuales contingencias, se ha visto obligada a abandonar el hermoso recinto de la población.»

A través de este tipo de fotografía, se propone al lector una mirada elegiaca y la nostalgia de un pasado idealizado. La imagen exhibe una sociedad pacífica, feliz, asociada a una historia legendaria, mientras que el texto insiste en la dimensión aterradora de la guerra, descrita como una invasión. La oposición entre la imagen y el texto forja el espacio de donde surge la «espectralidad» de las ruinas. El contraste genera el vacío a partir del cual esta «espectralidad» se vuelve efectiva para el lector, que percibe en estas dos fotografías los vestigios del patrimonio, las ruinas de una Euzkadi devastada. 
Esta visión desempeña un papel esencial en el discurso de los antifascistas y, en particular, en el de los nacionalistas vascos. Como en el caso alemán ${ }^{38}$, la presencia de estas fotografías se debe en parte al hecho de que la prensa debe franquear numerosos obstáculos para publicar clichés sobre los combates encarnizados que tienen lugar en aquel momento. No obstante, estos clichés y la manipulación de la que son objeto ponen de manifiesto la importancia que revisten las representaciones de la guerra, o sea la percepción que se tiene del conflicto tanto en la retaguardia como en el campo de batalla. Para los nacionalistas vascos, resulta fundamental imponer la idea de que la nación vasca constituye una realidad a punto de ser destruida, función que desempeñan unas fotografías de ruinas que fluctúan entre visibilidad y «espectralidad». A través de estas imágenes y de las representaciones que transmiten, se intenta asociar el enemigo al terror y a la barbarie de una forma mucho más elaborada que la que proponen las «tradicionales» fotos de guerra. De hecho, se insertan en una estrategia global que pretende, hasta cierto punto, renovar los métodos propagandísticos y alcanzar los objetivos siguientes: idealizar el combate y convencer de la necesidad de una movilización general. Para ello, se difunde la idea de que la lucha contra los militares y el alistamiento en las milicias vascas constituye un acto cuya finalidad es acabar con el caos y con la violencia extrema que fomentan los rebeldes y sus aliados. Recuperar la parte del territorio controlada por los franquistas es un acto fundamental para la supervivencia del pueblo vasco, porque no sólo es la tierra de la devastación sino también una tierra ultrajada que debe ser purificada mediante el sacrificio de la juventud de Euzkadi. En definitiva, la vuelta a los equilibrios de antaño y la supervivencia - reconstrucción - de la sociedad tradicional que proponen indirectamente las fotografías de Indalecio Ojanguren pasan también por la destrucción. Como recuerda Paul Ricoeur, «el gesto creador, que distingue, separa, mide y ordena, no puede diferenciarse del gesto criminal que acaba con la vida» ${ }^{39}$. La violencia, por tanto, esta «inscrita en el origen de las cosas, en el principio que crea destruyendo» ${ }^{40} \mathrm{y}$ al cual remiten estas fotografías de ruinas en su naturaleza intrínseca.

38 Ibidem, p. 413.

39 Paul Ricœur, Philosophie de la volonté. Finitude et culpabilité, (1960), Aubier, Paris, 1988 , p. 327.

40 Ibidem, p. 329. 